\title{
As Unidades de Pronto Atendimento como unidades de internação: fenômenos do fluxo assistencial na rede de urgências
}

\section{| ${ }^{1}$ Mariana Konder, ${ }^{2}$ Gisele O'dwyer |}

Resumo: A Rede de Urgência e Emergência (RUE) do município do Rio de Janeiro foi alvo de investimentos e reestruturação com a disseminação das Unidades de Pronto Atendimento (UPAs). Superlotação, baixa qualidade e integração comprometem a conformação dessa rede. Buscou-se analisar a organizaçáo e o funcionamento dos fluxos assistenciais estabelecidos na RUE, a partir do acesso ao leito hospitalar. Foram realizadas 36 entrevistas e análise de dados de bancos de dados primários e secundários, utilizando-se estatística descritiva e a análise exploratória. $\mathrm{O}$ acesso ao leito hospitalar é infrequente, sendo atendidas apenas 13\% das solicitaçóes totais. As solicitaçóes de leito oriundas das UPAs alcançaram percentuais maiores, 40\% para UTI e 36\% para clínica geral. No entanto, os cerca de $60 \%$ restantes, geralmente, recebem alta ou evoluem para óbito antes de alcançar um leito hospitalar, transformando as UPAs em unidades de internação. Outro fenômeno de destaque foi a relação conflituosa entre os componentes pré-hospitalares (atenção primária e UPA) na dinâmica do fluxo do Vaga Zero, comprometendo a continuidade do cuidado. É necessário aprimorar o nível de integração entre unidades que compóem a RUE bem como expandir e qualificar a retaguarda hospitalar.

> Palavras-chave: regulação e fiscalização em saúde; acesso aos serviços de saúde; serviços de saúde de emergência; assistência à saúde.

\footnotetext{
' Faculdade de Ciências Médicas, Universidade do Estado do Rio de Janeiro. Rio de Janeiro-RJ, Brasil (marianakonder@gmail.com). ORCID: 0000-0002-7787-4983.

2 DAPS, Fundação Oswaldo Cruz. Rio de Janeiro-RJ, Brasil (odwyer@ ensp.fiocruz.br).

ORCID: 0000-0003-0222-1205.
}

Recebido em: 03/01/2019 Aprovado em: 31/01/2019 Revisado em: 30/03/2019 


\section{Introdução}

A Rede de Urgência e Emergência (RUE) do município do Rio de Janeiro foi objeto de investimentos e reestruturação no período recente, num cenário políticoinstitucional favorável, em que as Unidades de Pronto Atendimento (UPAs) foram o fio condutor inicial. Essas unidades surgiram em 2007 no município do Rio de Janeiro, como iniciativa do governo do estado, pretendendo responder ao contexto de crise na saúde do município, que teve seu ápice em 2005. Aspectos políticos da proposta e os acordos intergovernamentais estabelecidos favoreceram rápida e ampla disseminação das UPAs no município do Rio de Janeiro e em diversas regiôes do estado. Todavia, o ritmo acelerado de implantação das UPAs não ocorreu associado às iniciativas de melhoria dos demais componentes de atenção às urgências, estas dependentes de planejamento integrado e atuação coordenada entre distintas esferas de governo (LIMA et al., 2015). Embora essas unidades tenham representado um elemento importante na estruturação da RUE, não houve a necessária mudança na estrutura de governança da rede (KONDER; O’DWYER, 2016). A fragmentação e a desarticulação institucional (intra e intergovernamental), assim como as disputas entre os governos no processo de condução da política, comprometeram a integração dos diversos componentes da atenção às urgências no estado (LIMA et al., 2015).

A estrutura de atenção às urgências no município do Rio de Janeiro inclui um número expressivo de serviços, ligados às diferentes esferas de governo, com perfis variados de atendimento: as unidades de atenção básica (clínicas da família, centros e postos de saúde); o componente pré-hospitalar móvel (Samu); o componente de atendimento pré-hospitalar fixo (UPA e Coordenação de Emergência Regional-CER); e as emergências hospitalares. Em que pese o número expressivo de serviços existentes, problemas relativos à superlotação, qualidade, resolubilidade e integração seguem comprometendo a conformação da rede de atenção às urgências (LIMA et al., 2015).

As dificuldades de acesso a hospitalizações e consultas com especialistas, a precariedade na realizaçáo de exames complementares de caráter ambulatorial e de maior complexidade, leitos de Unidade de Terapia Intensiva (UTI) e enfermaria em número insuficiente, além de relaçôes de trabalho precárias resultando em escassez de profissionais de saúde, sobretudo médicos, persistem como gargalos na estruturação da rede assistencial e obstáculos ao acesso à saúde equânime e oportuno (KONDER; O’DWYER, 2016). 
Um processo semelhante ocorreu com a atenção primária (APS). A expansão desse nível de atençáo resultou num aumento da demanda por acesso à atenção secundária. A necessidade de estruturar a regulação do acesso a serviços de diagnose e terapia e aos especialistas foi um impulso importante para a organização de práticas de regulação do acesso à assistência na rede de saúde no município do Rio de Janeiro (PINTO et al., 2017).

Esta pesquisa buscou analisar a organizaçáo e o funcionamento dos fluxos assistenciais estabelecidos na RUE, a partir do acesso ao leito hospitalar.

\section{Metodologia}

Compuseram o universo deste estudo os estabelecimentos da rede de urgência e emergência do município do Rio de Janeiro. Adotou-se a triangulação de dados como estratégia para suprir as possíveis deficiências das diferentes fontes de dados, bem como prover uma compreensão mais ampla de um fenômeno complexo e ainda pouco explorado (DESLANDES, 2015). Realizaram-se entrevistas semiestruturadas com visitas às unidades e análise exploratória de dados coletados a partir de bancos de dados primários fechados. Dum total de 36 entrevistas, foram seis gestores centrais: um federal, dois estaduais e três municipais. A Central Estadual de Regulação (CERRJ) e o Complexo Regulador do Município do Rio de Janeiro (CRMRJ) foram visitados a fim de conhecer sua dinâmica de funcionamento e rotina de trabalho, sendo realizadas quatro entrevistas, um médico regulador estadual e três municipais. Houve visitas e entrevistas em 08 de 14 UPAs municipais, com pelo menos uma unidade por área programática. O mesmo ocorreu com as UPAs estaduais, sendo 08 visitas e entrevistas dum total de 16 unidades. Visitas e entrevistas ocorreram em 05 Coordenaçôes de Emergência Regional (CERs). Estas são unidades que funcionam de forma independente como um pronto-atendimento de emergência com perfil de atendimentos clínicos, ligadas a grandes emergências hospitalares da esfera municipal. Foram entrevistados coordenadores do Núcleo Interno de Regulação (NIR) de 05 hospitais gerais: um municipal com emergência aberta, um municipal de retaguarda, um estadual com emergência aberta, um federal com emergência aberta e um universitário. Os temas abordados nas entrevistas foram: a organização do processo regulatório, considerando instâncias, atores e estrutura; os fatores intervenientes às práticas regulatórias; e as relações entre regulação, formação 
de redes de atenção à saúde e atuação das esferas governamentais. As entrevistas foram codificadas da seguinte forma: gestor federal, estadual ou municipal; UPA M ou UPA E, para municipal e estadual respectivamente, seguido de um número. Para as CERs, ficou a própria sigla, e os hospitais foram identificados pela esfera governamental à qual eram ligados.

Mediante autorização, foi obtido acesso às bases de dados fechadas utilizadas e alimentadas pela Secretaria Municipal de Saúde do Rio de Janeiro (SMS-Rio) no processo de regulaçáo de leitos. Essas bases de dados são o SISREG e a Plataforma SMS-Rio. Através do SISREG, as unidades de saúde realizam a solicitação de internação hospitalar, inserindo os dados de identificação do paciente, o tipo de leito solicitado e a história clínica, com resultados de exame complementares, justificativa de internação, código da doença (CID-10) e código de procedimentos SUS. As unidades são comunicadas dos leitos autorizados para seus pacientes através do SISREG e também por e-mail. A Plataforma SMS-Rio importa os dados referentes às solicitações do SISREG e permite a organização das solicitações em filas, além de facilitar o trabalho do regulador, pois reúne outras informações na mesma interface, como o espelho do censo dos leitos hospitalares. É na Plataforma SMS-Rio que é feita aprovação da solicitação e autorização de internação nos leitos; portanto, só foi possível importar o conjunto dos leitos regulados pela central nessa plataforma. As solicitaçôes de internação que não eram atendidas não eram visíveis na Plataforma SMS-Rio, não havendo como conhecer o desfecho da solicitação de internação que não obtinha autorização de internação hospitalar. Desse modo, houve a necessidade de consultar ambos os sistemas.

Os dados do SISREG foram importados em blocos mensais em arquivos do software Excel contendo as seguintes informaçóes: número da solicitação (inserida no SISREG), nome da unidade solicitante, data da solicitação, código internacional de doenças, nome da clínica (tipo de leito), nome do procedimento solicitado (tabela SUS). Os dados da Plataforma SMS-Rio também foram importados em blocos mensais em arquivos do software Excel contendo as seguintes informaçóes: número da solicitação (inserida no SISREG), nome do paciente, tipo de leito, sexo, grupo etário, nome da unidade solicitante, data e hora da oferta do leito que foi regulado, data e hora da ocupação (que equivale à autorização para ocupar o leito, e não a ocupação física do leito pelo paciente), nome da unidade executante, nome do regulador e nome do profissional que ofertou o leito. 
Os dados importados corresponderam ao período de setembro de 2016 a agosto de 2017. Nesse período foram inseridas 56.907 solicitações de internação no SISREG. Sendo 24.564 solicitaçôes de leitos de clínica geral e 8.310 solicitaçôes de leito de UTI adulto de todos os tipos. Considerando que as UPAs estaduais e municipais e os CERs municipais foram juntos responsáveis por 20.317 solicitações de clínica geral, 82,7\% do total, e 5.969 solicitações de UTI, 71,8\% do total, foram construídos dois bancos de dados com as solicitaçóes inseridas por essas unidades, um para leitos de clínica geral, outro para leitos de UTI. Desses bancos foram selecionadas amostras aleatórias, perfazendo $10 \%$ e $5 \%$ do total de solicitaçôes, respectivamente, o que resultou em 590 solicitaçóes de UTI adulto e 1.001 de clínica geral. Os tamanhos de amostra se apoiaram em autores (ROSCOE, 1975; ALRECK; SETTLE, 1995) que defendem que amostras entre 5\% e 10\% seriam suficientes para pesquisas exploratórias, pois aumentos adicionais no tamanho da amostra não agregariam mais informaçôes ao estudo.

Cada uma dessas solicitaçóes foi acessada no SISREG através do número da mesma a fim de coletar os seguintes dados: o desfecho da solicitação e o tempo decorrido entre inserção da solicitação e desfecho. Os desfechos principais foram: regulação/transferência para leito, alta médica (ou à revelia), óbito ou mudança de perfil. Houve solicitaçôes em que a consulta no SISREG não permitiu conhecer o desfecho da solicitação, pois a unidade solicitante deixou a solicitação em aberto, isto é, sem resposta. O tempo decorrido foi calculado a partir da contabilização do horário de inserção no sistema e o horário descrito para o desfecho em comentário inserido no sistema pela unidade solicitante ou pelo regulador. Quando não havia menção ao horário em que se deu o desfecho, era computado o horário da inserção no sistema do comentário que informava do mesmo.

A SES-RJ não autorizou o acesso à base de dados do Sistema Estadual de Regulação. Desse modo, os desfechos regulatórios das unidades estaduais foram observados apenas a partir do SISREG; porém, as unidades estaduais obtêm a maioria de suas vagas junto à central estadual de regulação. Desse modo, nos casos em que as UPAs estaduais não informaram através do SISREG o destino de seus pacientes, essa informação ficou inacessível pela indisponibilidade de acesso aos dados produzidos pelo Sistema Estadual de Regulação. O projeto foi aprovado pelos CAAEs 57132716.0.0000.5240 e 57132716.0.3001.5279. 


\section{Resultados e Discussão}

$\mathrm{Na}$ caracterização assistencial da rede de urgência e emergência foram evidenciados alguns fenômenos já mencionados na literatura (GAWRYSZEWSKI et al., 2012; KONDER; O'DWYER, 2016; LIMA et al., 2015; O'DWYER et al., 2016; O’DWYER et al., 2017a; O'DWYER et al, 2017b) sobre a integração na atenção às urgências. Muito destaque recebeu a dificuldade com a retaguarda hospitalar, principalmente quando observada a partir da perspectiva das UPAs. Em decorrência da pouca disponibilidade dessa retaguarda hospitalar, as UPAs e as CERs frequentemente têm permanecido com pacientes sob seus cuidados até haver melhora clínica, configurando situação em que o paciente obtém o cuidado em saúde não no hospital, mas numa "internação" em ambiente pré-hospitalar. Outro fenômeno de destaque foi a relação conflituosa entre APS, CERs e UPAs na dinâmica do fluxo de Vaga Zero.

\section{Algumas características assistenciais da RUE}

No período da pesquisa, foram 24.564 solicitaçóes de leitos de clínica geral inseridas no SISREG para apenas 3.239 leitos de clínica geral regulados pelo CRMRJ através da Plataforma SMS-Rio. Isso significa que apenas 13,2\% das solicitaçōes de leito de clínica geral foram atendidas. Salienta-se que no SISREG estão incluídas as solicitações municipais, estaduais e federais, mas os leitos regulados por essas últimas duas esferas não são sinalizados ou comunicados através da Plataforma SMS-Rio. A situação para Unidade de Terapia Intensiva não é muito diferente. Foram 8.310 solicitaçôes de leito de UTI Adulto (tipos I, II e III) no SISREG para apenas 936 leitos de UTI regulados pelo CRMRJ. Como esperado, o cenário da terapia intensiva é ainda mais grave, com apenas $11,3 \%$ das solicitaçôes de leito de UTI atendidas (COELHO, 2016; NEGRI FILHO, 2016).

Analisando as solicitaçóes inseridas no SISREG, os cinco tipos de leito mais frequentemente solicitados na RUE foram os de clínica geral, UTI tipo II, pediatria clínica, psiquiatria e ortopedia- traumatologia, com 24.577, 6.691, 6.538, 3.582 e 3274 solicitaçôes, respectivamente. Os entrevistados reportam realidade compatível.

Basicamente, para a gente é o leito clínico ou CTI ou pediátrico. (UPA M4)

Clínico e CTI. A enfermaria clínica sempre a demanda é maior, a solicitação. Mas, em contrapartida, o CTI é mais difícil de ter. (CER 5)

[...] o que mais faz a movimentaçấo nossa aqui é a de clínica médica e a de UTI. (UPA M7) 
As patologias que mais frequentemente justificaram internação hospitalar de urgência são apesentadas a seguir. De um total de 5.969 solicitaçóes de internação em UTI adulto inseridas por UPA e CER, 13,3\% não tiveram a patologia que motiva a internação especificada por meio da Classificação Internacional de Doenças 10a ediçâo (CID-10). Dentre as solicitaçôes inseridas com patologia especificada, 05 tipos de CID-10 são encontrados em 49,2\% do total de solicitaçôes, com importante destaque para doenças cardiovasculares e infecçóes. São eles: infarto agudo do miocárdio não especificado, acidente vascular cerebral não especificado, pneumonia bacteriana não especificada, pneumonia não especificada e edema pulmonar não especificado, respectivamente.

Quanto às solicitaçóes de internação em clínica geral, de um total de 20.317 inseridas por UPA e CER, 18,1\% não têm a patologia que motiva a internação especificada por meio da CID-10. Dentre as solicitaçóes inseridas com patologia especificada, 05 tipos de CID-10 são encontrados em 44,0\% do total de solicitaçôes, com semelhante destaque para doenças cardiovasculares e infecçóes. São eles: acidente vascular cerebral não especificado, infecção do trato urinário de localização não especificada, infarto agudo do miocárdio não especificado, pneumonia não especificada e pneumonia bacteriana não especificada, respectivamente. Problemas renais também surgem como importante diagnóstico para leitos de clínica geral. Destacam-se, porém, diagnósticos psiquiátricos e a tuberculose como justificativa de internação hospitalar. Diagnósticos como esquizofrenia paranoide, psicose não orgânica e transtorno bipolar compuseram as solicitaçôes para leitos de hospitais gerais. Igualmente chama atenção que 10,1\% das internaçôes em clínica geral em caráter de urgência se devam ao diagnóstico de tuberculose.

Analisando os dois tipos de leito mais solicitados, encontramos diferença significativa entre o número de solicitaçôes inseridas por unidades estaduais e municipais. No gráfico 1, observa-se a distribuição das solicitaçôes de clínica geral e UTI adulto inseridas por UPA e CER por esfera administrativa. Observase que a esfera estadual foi responsável por $14 \%$ das solicitaçôes de UTI e $21 \%$ das solicitaçôes de clínica geral, enquanto a esfera municipal foi responsável por $86 \%$ e $79 \%$, respectivamente. Considerando que o estado gerencia 16 UPAs e o município, 14 UPAs e 05 CERs, isso significa que as UPAs estaduais solicitaram 14,6 leitos de clínica geral por UPA/mês enquanto as UPAs/CERs municipais solicitaram 76,8. Isso representa um volume de solicitaçôes cinco vezes maior na 
esfera municipal. Para os leitos de UTI, as UPA estaduais solicitaram 6,5 vagas por UPA/ mês, enquanto as UPAs/CERs municipais solicitaram 20,7 por UPA/mês, um volume três vezes maior de solicitações. Essa discrepância no volume de solicitaçôes de internação é intrigante. Uma hipótese é a de que a solicitação de vagas por parte das UPA estaduais ocorreria prioritariamente ou exclusivamente via SER, sistema de regulação ao qual o acesso não foi autorizado, o que poderia clarificar a origem dessa diferença. No entanto, de acordo com os entrevistados, as UPAs estaduais solicitavam vagas simultaneamente no SISREG e no SER. Outro possível elemento explicativo diz respeito ao volume de atendimento dessas unidades. Contudo, náo foi possível obter esses dados, no âmbito da presente pesquisa. Tal informação poderia potencialmente auxiliar a compreender essa significativa diferença.

Gráfico 1. Distribuição das solicitaçôes de Clínica Geral e UTI Adulto inseridas por UPA e CER por esfera administrativa - Rio de Janeiro/RJ - setembro de 2016 a agosto de 2017

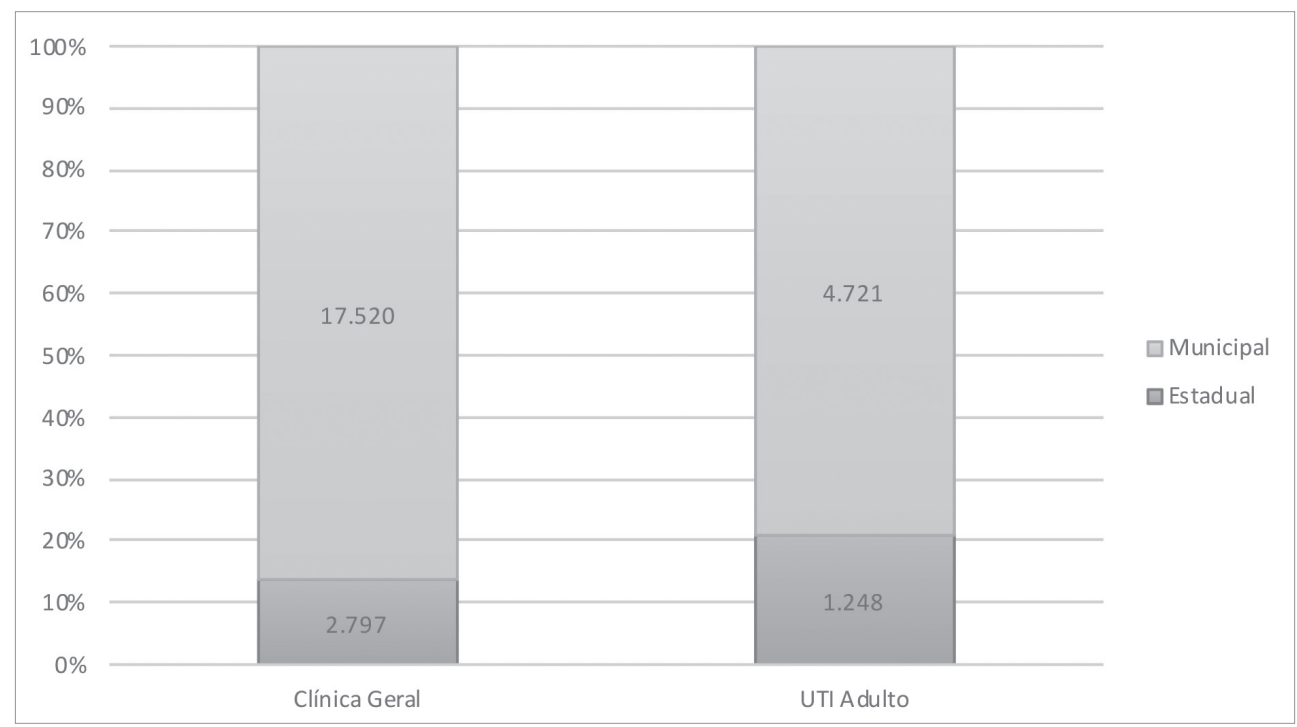

Fonte: SISREG

No gráfico 2, apresentam-se as solicitações de internação hospitalar por tipo de leito ao longo de 12 meses. Observa-se que o número de solicitaçóes de internação hospitalar para adultos é bem maior do que para pacientes pediátricos. Para os leitos adultos, observa-se uma tendência de reduçáo das solicitaçóes de uma forma geral nos dois últimos meses do ano de 2016 e nos três primeiros meses de 2017, o que pode ser 
relacionado com o período de férias. Já os leitos pediátricos têm uma demanda estável, que se avoluma no período de março a julho, com picos em maio e junho, devido ao aumento da incidência da bronquiolite, infecção respiratória comum entre crianças.

Gráfico 2. Distribuiçáo das solicitaçóes de internação hospitalar por tipo de leito por mês - Rio de Janeiro/RJ - setembro de 2016 a agosto de 2017

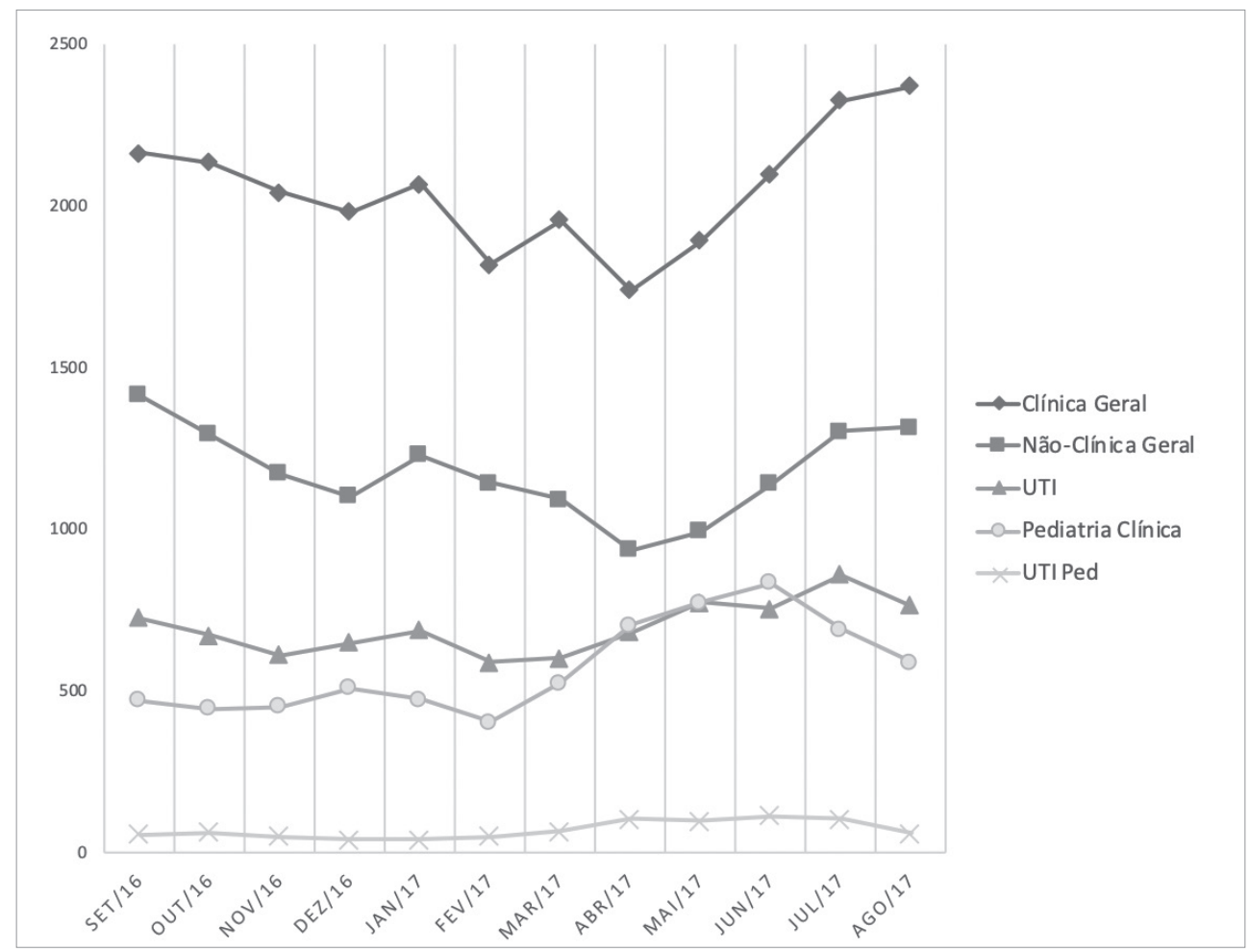

Fonte: SISREG

\section{A UPA como unidade de internaçáo}

Um fenômeno frequentemente observado nas UPAs foi o tempo de espera pelo leito ser bastante longo, extrapolando o período de observação de 24 horas preconizado na legislação para estabilização clínica e elucidação diagnóstica (BRASIL, 2017). Entretanto, a permanência de pacientes em serviços de emergência por períodos superiores a quatro horas está associada a progressivo aumente no tempo de permanência, no grau de morbidade e nos custos (LIEW; KENNEDY, 2003). Devido às dificuldades para disponibilização dos leitos solicitados, frequentemente 
os pacientes permanecem nessas unidades aguardando leito, seja de enfermaria, seja de UTI. Alguns inclusive por longos períodos.

Muitas vezes o paciente vai ficar aqui dois ou três dias e vai ser liberado, sem essa necessidade. Como falei da infecção urinária complicada, a erisipela... (UPA M4)

[...] sair um paciente daqui para ir para uma enfermaria de clínica médica é quase impossível. (UPA M6)

Para avaliar esse fenômeno, foram analisados os desdobramentos dos dois tipos de perfil de leito, UTI e clínica geral, que tiveram o maior número de solicitaçôes inseridas no SISREG no período desta pesquisa.

Analisando o desfecho das solicitaçóes de UTI (gráfico 3-A), das 590 amostradas, $40 \%$ foram reguladas para leito de UTI, 23\% evoluíram para óbito, 17\% receberam alta médica e $13 \%$ evoluíram com melhora clínica, exigindo a mudança do perfil de leito solicitado. Destaca-se o percentual elevado de solicitaçóes de UTI que são atendidas com a designação de um leito hospitalar, sobretudo quando se coteja esse dado com a média de 11,3\% de solicitaçôes de UTI atendidas com leito. A discrepância, provavelmente, se explica pela prioridade que essas unidades préhospitalares recebem para regulação de leito de UTI em comparaçáo com as solicitaçóes feitas por unidades hospitalares.

\section{Gráfico 3. Distribuiçấo do desfecho das solicitaçóes de UTI e Clínica Geral - Rio de} Janeiro/RJ - setembro de 2016 a agosto de 2017
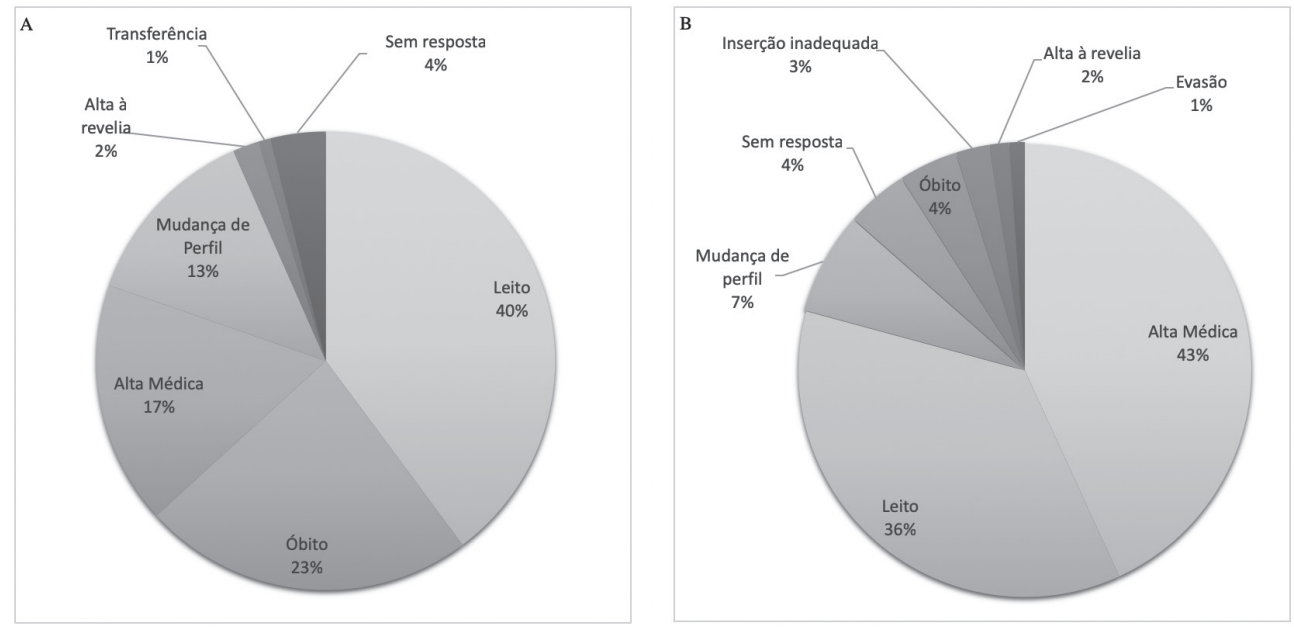

Fonte: SISREG - Dados amostrais

Legenda: A: UTI; B: Clínica Geral 
No gráfico 4-A é apresentado o tempo que cada solicitação de UTI da amostra levou para ser atendida com a regulação para um leito. Ressalva-se que, na maioria dos casos, o tempo apresentado mede o intervalo entre a inserção da solicitação no sistema, desconsiderando o tempo decorrido desde a chegada à unidade, e a informação do leito disponibilizado, desconsiderando o tempo de remoção entre UPA/CER e hospital de destino, que muitas vezes não é curto. Observa-se que apenas 30,8\% das solicitaçôes são atendidas nas primeiras 24 horas. A maioria das solicitaçôes tem o leito disponibilizado após 24 horas, atendendo a 48,7\% das solicitaçóes entre 24 e 96 horas.

Esse cenário de espera pelo leito leva a circunstâncias inesperadas em que os cuidados e recursos necessários para o paciente são incompatíveis com a unidade pré-hospitalar, como a nutrição enteral e a hemodiálise.

A minha [sala] vermelha tem 14 leitos, eu já tive doente que ficou 35 dias. Como é que eu vou deixar um paciente grave, entubado, sem dieta enteral? (CER 5)

A gente não tem hemodiálise prevista em contrato para unidade pré-hospitalar, só que a gente começou a fazer porque a gente começou a perder doente. (CER 5)

Hoje o maior prejuízo que eu vejo é dos pacientes extremamente graves, quanto maior o tempo que ele permanece na unidade, é mais tempo que ele fica sem nutrição, é mais tempo que ele fica em respirador inadequado, sem a fisioterapia respiratória necessária, então ele perde massa muscular e para depois você recuperar esse paciente, é pior. (UPA E5)

Em outra direção, observa-se no gráfico 3-A que 53\% das solicitaçôes de UTI saíram da fila da regulação antes da liberação do leito, sendo que em 17\% dos casos o paciente recebeu alta médica da própria UPA ou CER. Outros 13\% tiveram seu perfil de leito modificado, presumidamente por melhora clínica e outros $23 \%$ evoluíram para óbito.

No gráfico 4-B, é apresentado o tempo entre a inserção da solicitação de UTI e a alta médica da unidade. Observa-se que $50 \%$ das altas médicas ocorrem nas primeiras 48 horas após a inserção da solicitação de UTI. No gráfico 4-C, apresentase o tempo entre a inserção da solicitação de UTI e a solicitação de mudança de perfil de leito. Observa-se que 40,8\% das solicitaçôes de mudança de perfil ocorrem nas primeiras 48 horas após a inserção do pedido de UTI. O perfil de mudança mais solicitado é o de clínica geral.

O elevado percentual de solicitações canceladas por alta médica ou mudança de perfil, sobretudo nas primeiras 48 horas, levanta dúvidas quanto aos motivos dessa proporção significativa de saídas da fila. Em seu estudo, Goldwasser et al. (2016) 
observou números semelhantes e apontou a necessidade de buscar compreender se tal fenômeno se explica pela eficiência da atenção pré-hospitalar ou se por inadequação a priori dos critérios de indicação da vaga de UTI. Se, por um lado, o atendimento adequado no ambiente pré-hospitalar, mediante protocolos assistenciais, pode ser responsável pela melhora clínica e de prognóstico, evitando indicação de UTI (GOLDWASSER et al., 2016); por outro, o fluxo administrativo interno das unidades pode estar contribuindo para um processo acelerado de inserção de solicitações, podendo produzir uma demanda por UTI superestimada.

Até porque a gente tem uma cobrança. Mensalmente a gente tem um relatório de metas. Entâo, o paciente não pode estar há mais de 24 sem ter sido lançado [no SISREG]. (UPA M4)

O tempo decorrido entre a inserçáo da solicitação de UTI e o cancelamento da mesma porque o paciente evoluiu para óbito é apresentado no gráfico 4-D. Observase que $39 \%$ dos óbitos ocorrem nas primeiras 24 horas. Muito possivelmente, esses pacientes já chegaram às unidades fora de possibilidade de cura. Outros $31,7 \%$ vêm a falecer entre 24 e 48 horas, e após 48 horas são mais 29,3\% de óbitos. Fica a interrogação se os óbitos ocorridos a partir de 24 horas de espera não seriam óbitos evitáveis caso esses pacientes tivessem tido acesso a um leito de UTI.

Gráfico 4. Distribuição das solicitaçôes de UTI Adulto conforme tempo para desfecho alta hospitalar, leito regulado, óbito e cancelamento por mudança de perfil - Rio de Janeiro/RJ - setembro de 2016 a agosto de 2017

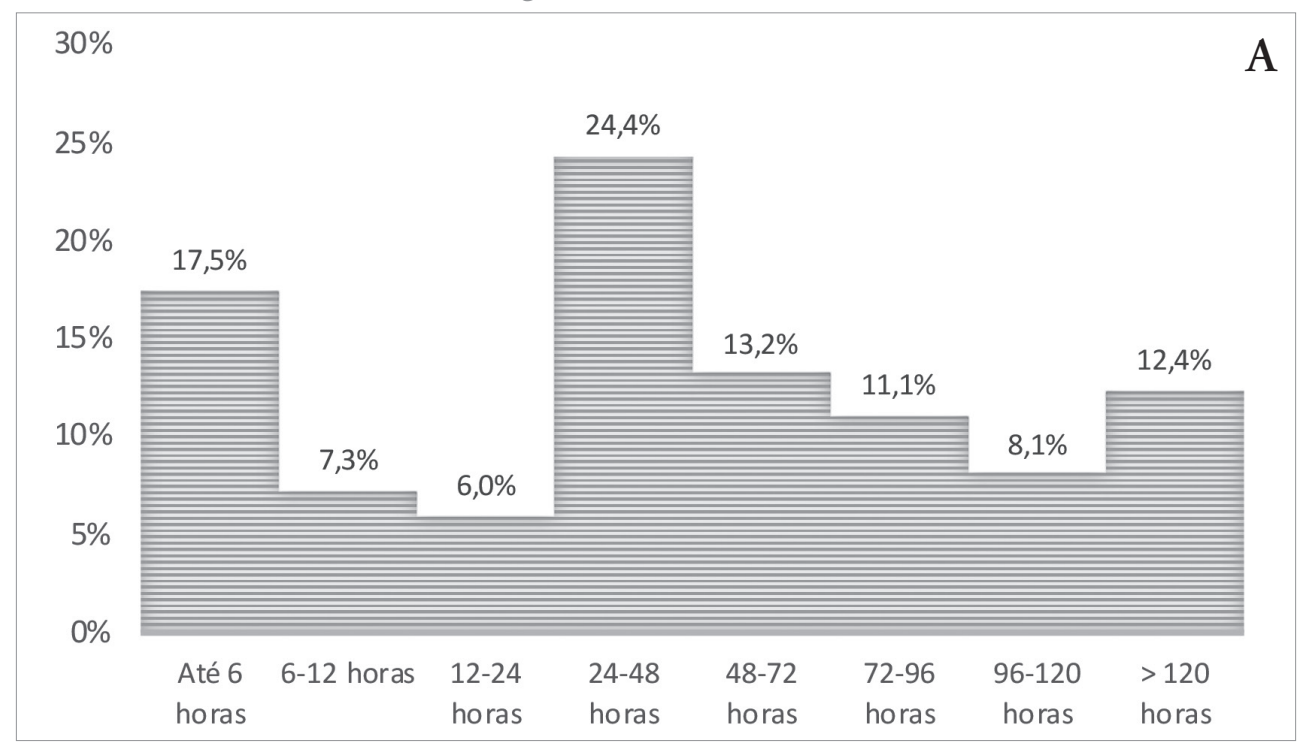



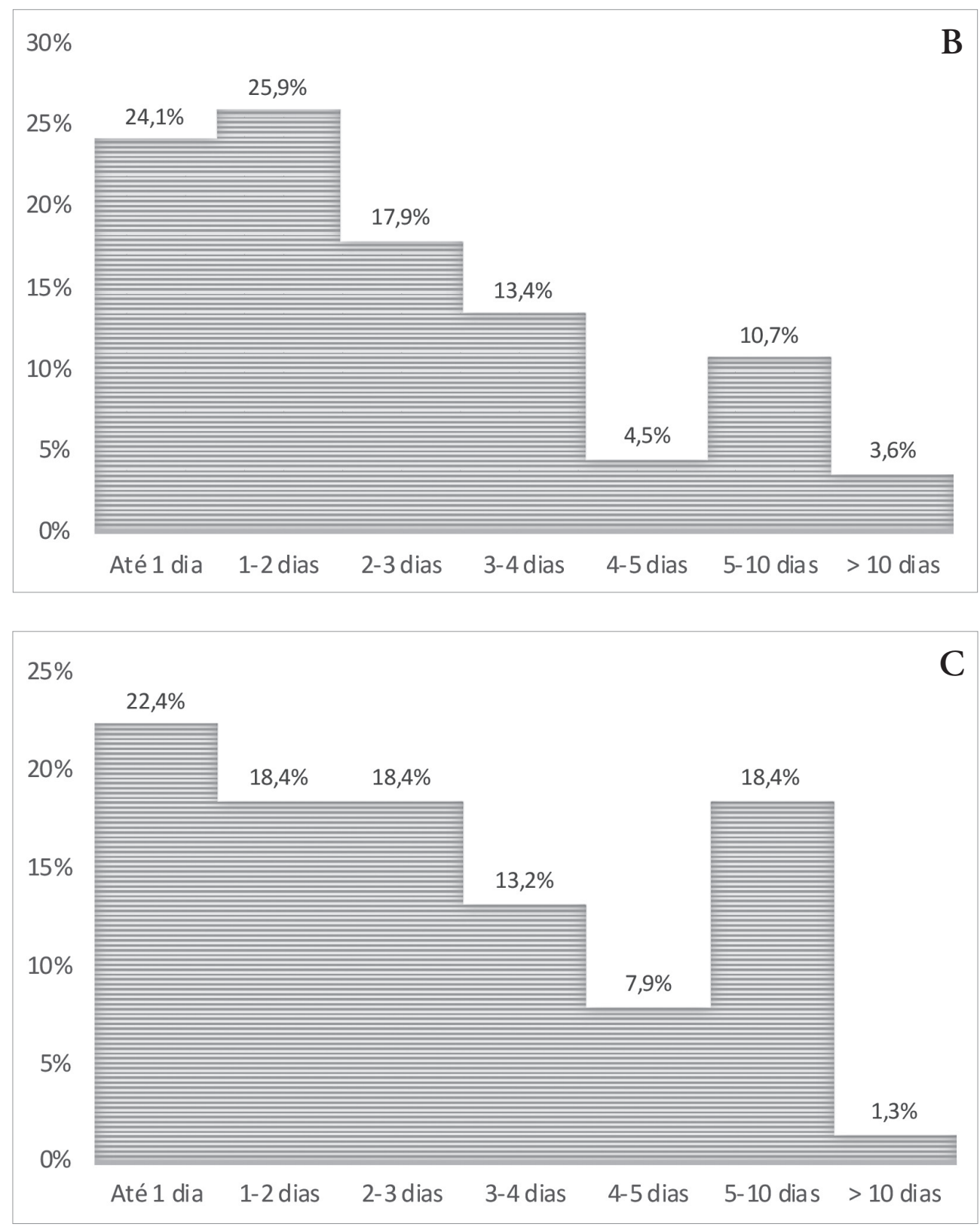


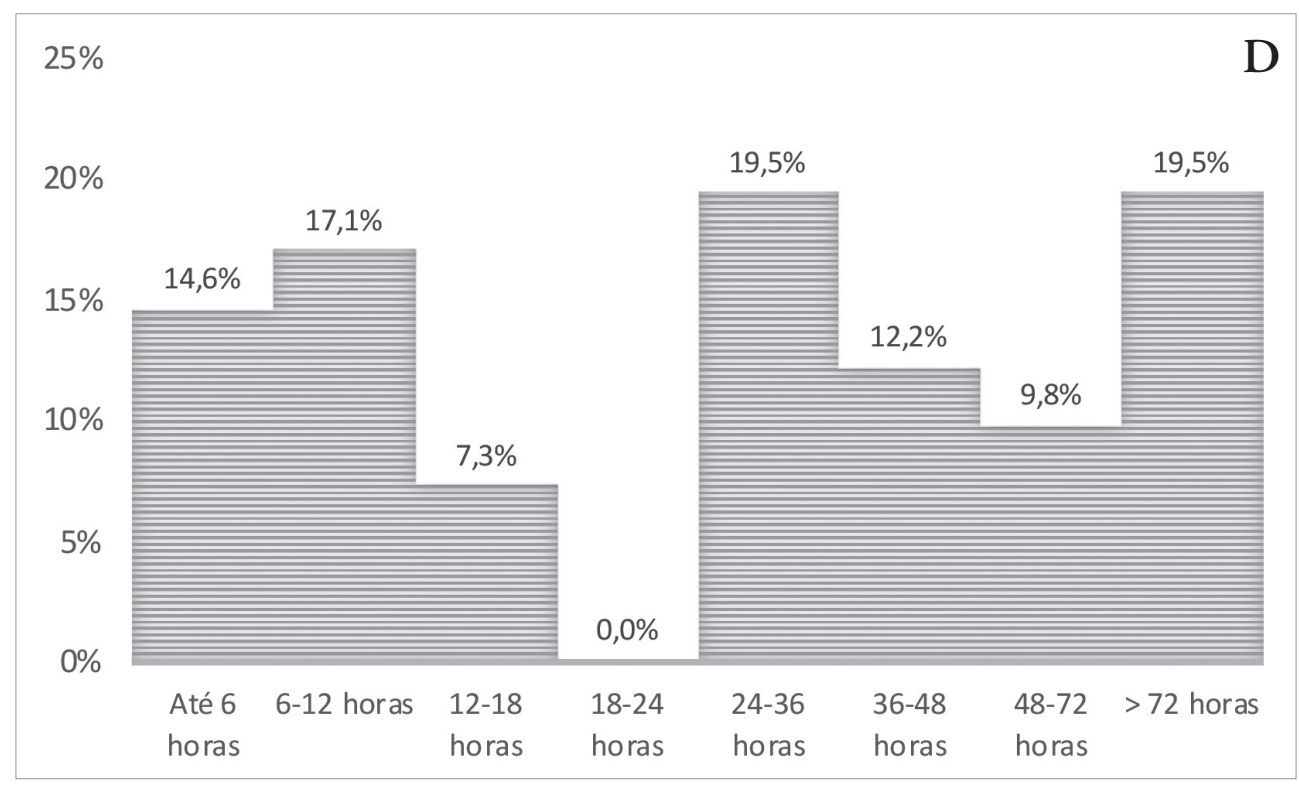

Fonte: SISREG - Dados amostrais

Legenda: A: Leito regulado; B: Alta hospitalar; C: Cancelamento por mudança de Perfil; D: Óbito

Outro desdobramento frequente do cenário de espera é o da "internação" na UPA. Nessas circunstâncias, os pacientes são atendidos, recebem um diagnóstico, têm um tratamento iniciado e terminam por receber alta com melhora do seu quadro clínico antes de ser regulado para um leito de clínica geral, principalmente, mas também de UTI.

Tem muito paciente que fica aqui três, cinco, seis dias e recebe alta e fica bem, até porque a gente tem um suporte para isso. (UPA M8)

Tem pacientes aqui que eu dou alta, eu estou aqui com uma infartada que tá no quinto dia, chegar no décimo dia não evoluiu, tá muito bem obrigada, eu dou a recomendação, exames que foram feitos e ela vai para a clínica da família ver se vai fazer um cateterismo, porque não sai. Então, esse paciente é um paciente que tá evoluindo bem e tem que fazer cateterismo, mas não faz, eu mando embora. Ou então, tem muitos clientes que pedem alta, não querem mais ficar, alta à revelia mesmo. (UPA M6)

Analisando o desfecho das solicitaçôes de clínica geral amostradas, foi observado que em $43 \%$ delas os pacientes receberam alta médica antes de serem regulados para um leito hospitalar; para 36\%, foi atribuído um leito hospitalar; $7 \%$ foram canceladas por mudança de perfil clínico; $4 \%$ evoluíram para óbito; $2 \%$ foram de 
alta à revelia da recomendação médica; e $1 \%$ foram evasôes do estabelecimento de saúde (gráfico 3-B).

Não foi possível avaliar o desfecho de $4 \%$ das solicitaçôes, pois não houve resposta da unidade solicitante após a primeira apreciaçáo do CRMRJ. Do total de solicitações da amostra, 3\% corresponderam à inserção inadequada da solicitação. Foram duas as ocorrências predominantes: ou o perfil do paciente náo era compatível com o perfil de leito, em geral porque o paciente era pediátrico, ou o perfil de leito não era compatível com o quadro clínico do paciente, em geral um quadro de maior gravidade demandando leito de UTI.

As análises acima são no todo compatíveis com a percepção dos entrevistados de que o desfecho mais comum de um paciente para quem é solicitado um leito de clínica geral através do SISREG na RUE é receber alta médica antes de ter o leito regulado. $\mathrm{O}$ tempo decorrido entre a inserção da solicitação de clínica geral e a alta médica da unidade é apresentado no gráfico 5-A.

Observa-se que $52,5 \%$ das altas médicas ocorrem nas primeiras 48 horas após a inserção da solicitação de clínica geral. Esse achado é compatível com a percepção dos entrevistados de que dentre esses pacientes predomina a alta precoce.

Poucos dias. Vamos colocar aqui a grande maioria: 48 horas, a grande maioria. (UPA M1)

Apenas 16,1\% recebem alta médica com mais de quatro dias após a inserção da solicitação.

A gente tem muitas vezes o infartado que tá compensado, não tá no tubo, não tá nada... e a gente pede internaçáo e não consegue, então você passa com ele aqui uma semana, você faz uma curva enzimática, não tá mais com enzima elevada, então ele vai acabar saindo de alta daqui, mesmo ele regulado. (UPA M8)

Considerando que o tempo médio de internação hospitalar por todas as causas da OCDE em 2015 foi de oito dias (OECD, 2017) e que o universo dessas solicitaçóes é de quadros clínicos, com predomínio de pacientes idosos, o tempo demasiado curto entre inserção da solicitação e alta médica suscita dúvidas quanto à pertinência seja da alta, seja da solicitaçáo de internação.

Esse fenômeno é tão frequente que as equipes das UPAs já começam a tratar com naturalidade sua ocorrência, a ponto de considerar como razoável que a permanência na UPA substitua uma internação hospitalar. 
Tem casos que a gente sabe que não teria necessidade de ocupar um leito hospitalar, que poderia ficar aqui. (UPA M5)

Teoricamente, a UPA não foi feita para isso. A UPA seria aquela porta de entrada, só que a gente entende que o hospital por estar superlotado e a UPA tendo condições de resolver a vida desse paciente em dois, três dias e resolvendo, e resolvendo bem, a gente náo se incomoda e o paciente também não. (UPA E2)

A ocorrência de internaçóes nas UPAs foi observada como fenômeno frequente, representando uma distorção da finalidade e das possibilidades de cuidado dessa unidade (O'DWYER et al., 2017b).

Em relação às solicitações de clínica geral que efetivamente obtêm um leito regulado (gráfico 3-B), apesar de apenas 36\% serem atendidas, contribuindo para o fenômeno da internação na UPA, destaca-se que esse percentual é elevado considerando a média geral de $13,1 \%$ de solicitaçôes de clínica geral atendidas com leito. Assim como no caso dos leitos de UTI, tal discrepância provavelmente se explica pela prioridade que essas unidades pré-hospitalares recebem para regulação de leito de UTI em comparação às solicitações feitas por unidades hospitalares. As CERs e UPAs solicitaram 20.317 dos 24.564 de leitos de clínica geral inseridos no SISREG. No gráfico 5-B observa-se que 49,6\% dos leitos regulados são oferecidos nas primeiras 48 horas.

Quanto à mudança de perfil das solicitaçóes de clínica geral, 36,6\% ocorrem nas primeiras 24 horas, alcançando 59,6\% em 48 horas (gráfico 5-C) - considerando que $78 \%$ das mudanças são solicitaçôes de leito de UTI, sinalizando um agravamento do quadro clínico do paciente. Esse percentual elevado de mudanças por agravamento suscita dúvidas quanto à pertinência da indicação inicial de leito de clínica geral. $\mathrm{Na}$ mesma direção, a ocorrência de 45,2\% dos óbitos nas primeiras 48 horas (gráfico 5-D) também contribui para o questionamento da adequação da solicitação. 
Gráfico 5. Distribuição das solicitaçôes de Clínica Geral conforme tempo para desfecho alta hospitalar, leito regulado, óbito e cancelamento por mudança de perfil - Rio de Janeiro/RJ - setembro de 2016 a agosto de 2017
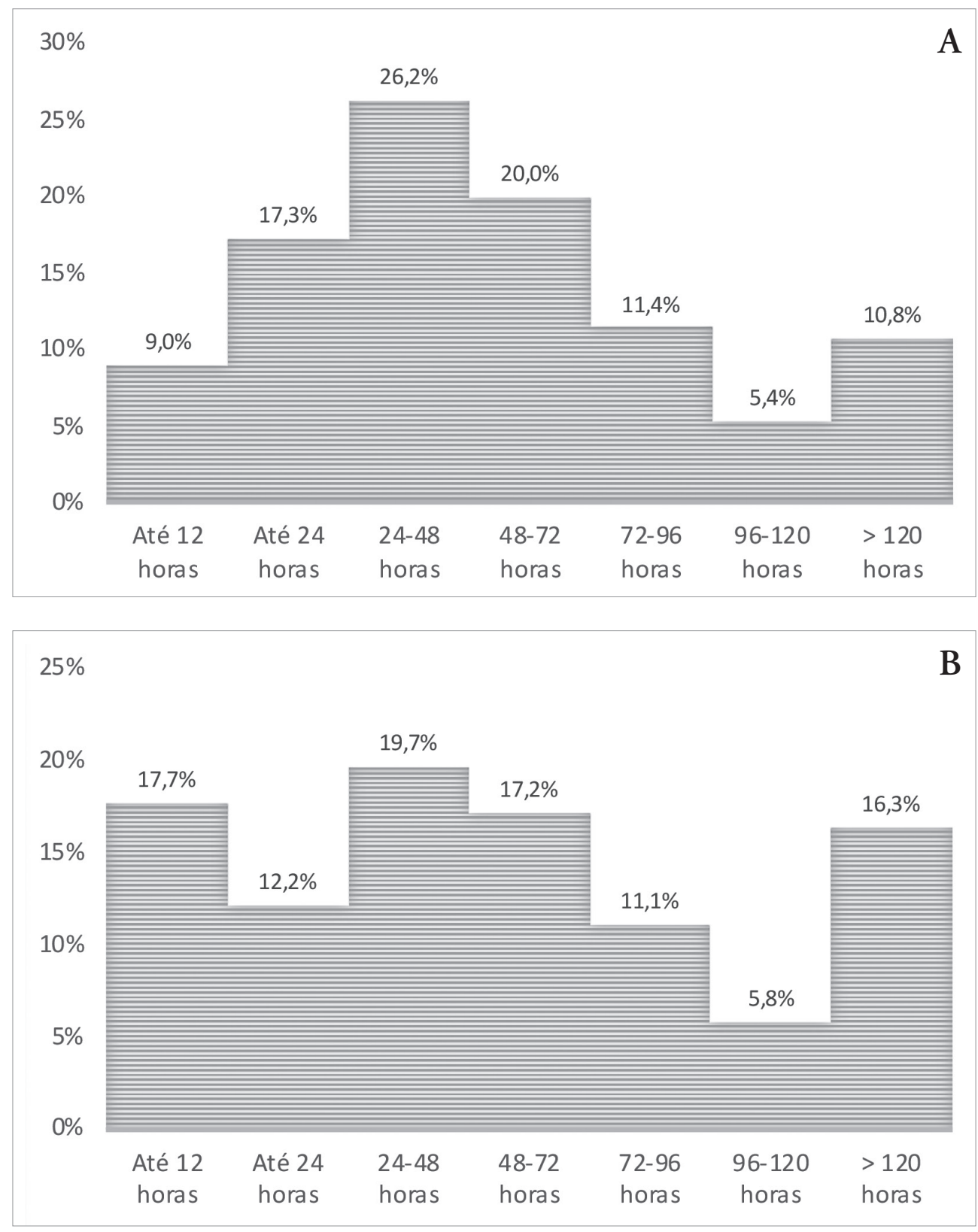

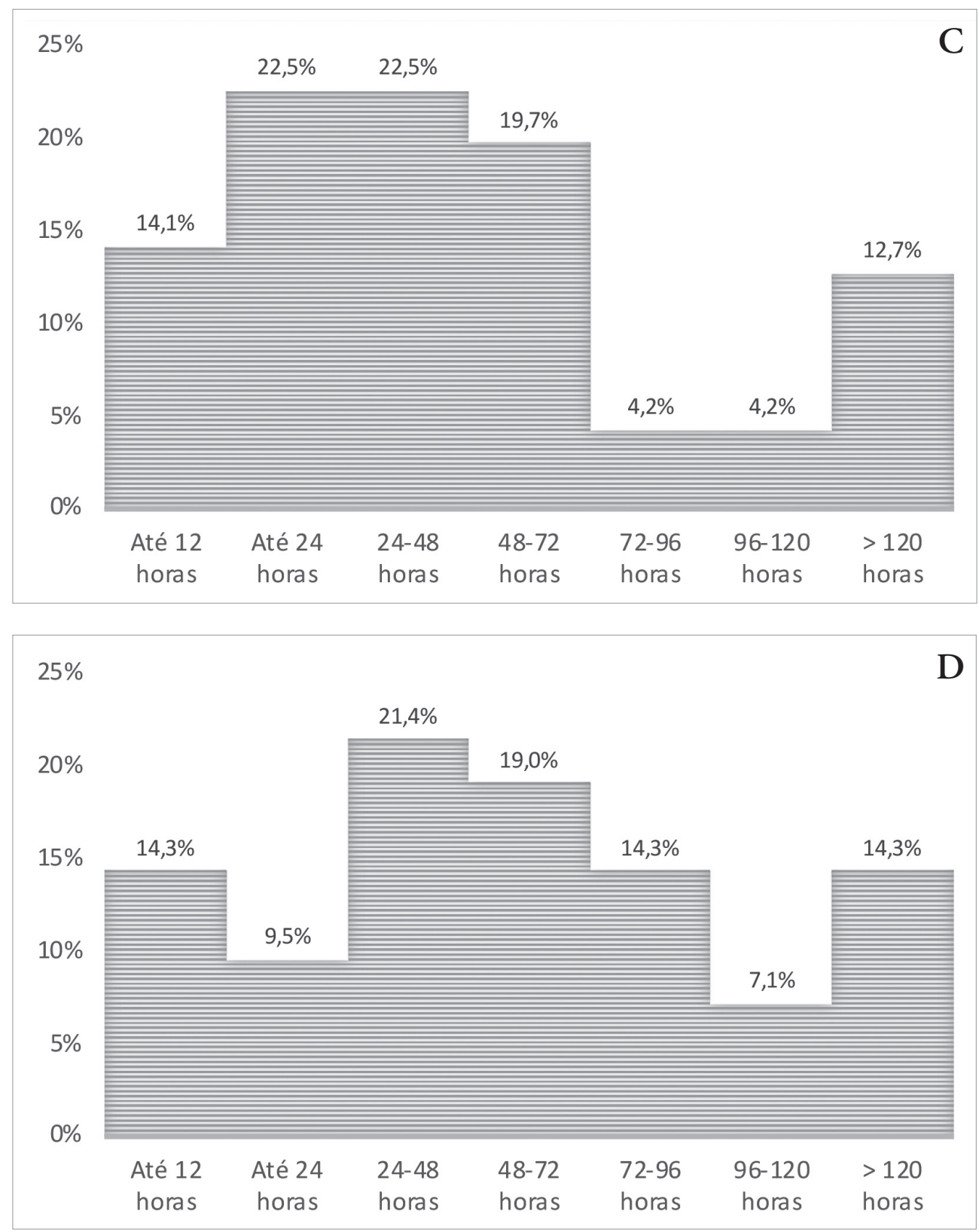

Fonte: SISREG - Dados amostrais

Legenda: A: Alta hospitalar; B: Leito regulado; C: Cancelamento por mudança de Perfil; D: Óbito 


\section{Vaga zero da APS: cenário de conflitos}

Na RUE no município do Rio de Janeiro existe uma modalidade de regulação denominada Vaga Zero. Nessa categoria incluem-se todas as circunstâncias clínicas de completa desassistência, representando risco iminente para a manutenção da vida, como no caso de um paciente com insuficiência respiratória numa unidade básica de saúde, cujos recursos disponíveis são insuficientes para a preservação da vida. Outra situação é a de inadequação da assistência, quando a unidade não dispóe de recursos para o adequado tratamento de uma condição potencialmente fatal, mas sem risco imediato para a preservação da vida. Como no caso do diagnóstico clínico de acidente vascular cerebral requerendo a precoce realização de tomografia computadorizada de crânio a fim de direcionar o tratamento subsequente; da suspeita de abdome agudo cirúrgico, requerendo avaliação de especialista e realização de tomografia computadorizada de abdome; da estimativa da extensáo e gravidade de lesóes em pacientes vítimas de traumatismos.

O recurso da Vaga Zero acomoda tanto o acesso a recursos mínimos de sobrevivência quanto o acesso a recursos críticos para diagnóstico e tratamento em casos de grande potencial de morbidade e mortalidade. Do texto da Lei $\mathrm{n}^{\circ}$ 2.048/2002, depreende-se que o conceito de Vaga Zero ensejaria a emergência hospitalar como destino final do paciente. No entanto, a realidade no município do Rio de Janeiro conta com uma diversidade maior de respostas para uma variedade de situaçôes classificadas como Vaga Zero, podendo a UPA ou CER ser a unidade de destino da regulaçáo de Vaga Zero, principalmente quando solicitada pela APS. Outra circunstância é a regulação para a emergência hospitalar ser restrita à realização da avaliação por especialista, com retorno do paciente para a UPA ou CER. No que diz respeito à dinâmica do Vaga Zero envolvendo UPA/CER e APS, encontra-se um cenário de conflitos.

As UPAs e CERs relatam graves inconsistências nas demandas de Vaga Zero oriundas da APS. Para um dos entrevistados, o conflito reside em haver diferentes visóes sobre urgência.

A maioria das vezes a visão da urgência do médico que é de Clínica da Família, [...], é diferente de quem trabalha em UPA, e são discordantes várias vezes. (UPA M8)

O que eu percebo muito é que por vezes o médico da saúde básica, ele por não ter essa vivência, essa prática de emergência, ele acha que muita coisa é emergência e não é. (UPA M7) 
Outro entrevistado, apesar de reconhecer a posição mais frágil da APS no atendimento às situaçóes de urgência, aponta que a Central poderia atuar para qualificar essas solicitaçóes.

Eu costumo dizer que os nossos Vagas Zero são avaliados por eles, eu acho que eles poderiam também filtrar ou avaliar as Vagas Zero que vêm das Clínicas da Família. [...] Eu acho que faz parte do instrumento também de qualificação da rede. E isso a gente não tem. (UPA M2)

E eu acho que a regulação não, ou o pessoal da Vaga Zero, não esmiúça esse caso para ver se realmente vale. (UPA M6)

Na visão dos profissionais e gestores das UPAs e CERs, as solicitaçôes de Vaga Zero são frequentemente inadequadas.

É uma questão que gera bastante discussão. Pela avaliação dos médicos, são muitos casos desnecessários. Tanto para mais quanto para menos. Tem pacientes que são regulados para UPA que deveriam ir direto para uma complexidade maior e acabam vindo para cá para fazer pit stop, vem e é inserido na Vaga Zero. E outros casos que não, que não haveria necessidade, que daria para fazer a medicação na própria atenção básica. (UPA M5)

Destacou-se a percepção de que, por vezes, a avaliação diagnóstica da APS é precipitada e que o recurso do Vaga Zero é utilizado para transferir o problema daquele paciente para outra instância. Há mesmo a queixa de que os relatórios do Vaga Zero exageram deliberadamente a situação crítica do paciente:

Eu já recebi uma Vaga Zero "paciente entubado, choque anafilático, de picada de abelha", aí falei com todo mundo: "prepara a sala vermelha". Aí paciente chega andando, falando "porque médica achou que ia ter que entubar". (UPA M8).

Sessenta por cento inadequado ou mais, tem dia que a gente já sabe que é o "retira doente da unidade". Coisas que náo tem... Às vezes a gente observa que o doente nem foi visto de forma adequada e eles pedem leito. A ambulância é rapidamente liberada para eles tirarem a Vaga Zero da clínica da família e quando escreve uma coisa e chega aqui outra. (CER 3).

Acontece de eles regularem como Vaga Zero e chegar aqui o paciente não querer nem ficar! Eles pioram o quadro clínico de uma tal forma que quando chega aqui... Poxa, nós montamos um aparato! Nós vamos esperar um paciente com o quadro clínico muito pior do que quando ele chega aqui. Aí, às vezes, ele não vai pra sala amarela! Vem, faz a ficha que vai pro consultório, realizam-se alguns exames, ele aguarda normalmente aqui, sentadinho, e não há nem a necessidade de internação. (UPA M1).

Principalmente no final do dia, para despachar o doente para cá. E é muito complicado. (UPA CDD).

[...] já vi pacientes que você olha para o relato do colega, olha para o paciente e não bate. (UPA M7) 
Essa situação por vezes culmina com uma incompatibilidade entre a expectativa do paciente removido via Vaga Zero e o perfil de atendimento e recursos existentes na UPA.

[...] o paciente vem com o discurso de que vai internar ou de que vai passar pela avaliaçáo do especialista. Então, ele já chega aqui na UPA achando que vai passar por um cirurgião vascular, achando que vai passar por algum especialista, né, e normalmente são muito mal orientados. (UPA M2).

Como é regulaçấo e como ele chega em Vaga Zero, eu não posso recusar, eu aceito e logo depois dou alta. E aí tem muitos doentes que reclamam, que não sabem nem o que estão fazendo aqui. (UPA M6).

Contudo, nem tudo são discordâncias. Existem situaçóes em que a UPA reconhece que é demandada a acolher uma Vaga Zero oriunda da APS de forma pertinente. Admitindo que dispóem de maior densidade tecnológica que pode ser utilizada no melhor interesse e condição clínica do paciente.

[...] no caso do idoso com pneumonia: eles estâo sendo acompanhados pela Clínica da Família de fora, a medicação não está surtindo efeito, aí o idoso cai e ele piora. E aí eles inserem na plataforma de Vaga Zero, e eles acabam regulando pra cá justamente pra gente acolher. [...] Manter esse idoso em observação com a medicação que geralmente é complementar ou substituída, mas que ele vai ficar monitorado aqui por nós. (UPA M1).

Toda unidade básica, ela tem que ter um suporte, ela tem que ter uma retaguarda emergencial. Aqui a nossa UPA serve como retaguarda a todas as unidades básicas aqui da área. (UPA M7).

Alguns chegam a reconhecer um percentual significativo de demandas bem solicitadas.

Algumas são importantes e, não digo metade, mas uns 40\%. (UPA M8).

No entanto, as UPAs e as CERs não produzem análises para devolutivas sistemáticas à central quanto à inadequação dos encaminhamentos de Vaga Zero oriundos da APS. Salvo situações de extrema discrepância.

Quando chega uma situação absurda, óbvio que a gente fala, mas o resto a gente tenta resolver. (UPA M8).

Nas reunióes que tem mensais, quando é pertinente, é uma reunião que a gente tem com todos dos diretores de CER, UPA..., a gente fala, mas isso daí é mais uma das coisas que não avançam. (UPA M8). 


\section{Considerações finais}

Este estudo logrou quantificar a grande discrepância entre o número de solicitaçôes de internação em leito hospitalar e o de vagas disponíveis, ainda que as unidades pré-hospitalares (UPAs/CERs) tenham sido ligeiramente privilegiadas. Esse fenômeno geral na RUE do município do Rio de Janeiro é acompanhado de outro: o da distorção da finalidade das UPAs, transformadas na prática em unidades de internação de curta duração, como já apontado em outros estudos, sendo quantitativamente explorado e caracterizado nesse. A naturalização das UPAs como unidade de internação para quadros clínicos constitui um falseamento que mais acomoda a falta de leitos em vez de tensioná-la. Adicionalmente, os dados produzidos permitiram lançar luz sobre questôes pertinentes à qualidade e à adequação das decisóes regulatórias tomadas no interior das unidades de saúde, pouco analisadas na literatura. Por fim, identificaram-se a persistência das visôes divergentes de urgência no interior da RUE e o impacto disso nas relaçôes entre profissionais e unidades. ${ }^{1}$

\section{Referências}

ALRECK, P. L.; SETTLE, R. B. The Survey Research Handbook. 2nd edition. Chicago: Irwin, 1995. $470 \mathrm{p}$.

BRASIL. Ministério da Saúde. Portaria de Consolidação no 3, de 28 de setembro de 2017. Consolidação das normas sobre as redes do Sistema Único de Saúde. Diário Oficial da União, Brasília, DF, 3 out. 2017 p. 192.

COELHO, I.B. Os hospitais no Brasil. São Paulo: Hucitec, 2016. 221 p.

DESLANDES, S. F. Revisitando as metodologias qualitativas nas pesquisas de avaliaçáo: vertentes, contribuições e desafios. In: BAPTISTA, T. W. F (Org.). Políticas, planejamento e gestão em saúde: abordagens e métodos de pesquisa. Rio de Janeiro: Editora Fiocruz, 2015. p. 193-217.

GAWRYSZEWSKI, A. R. B.; OLIVEIRA, D. C.; GOMES, A. M. T. Acesso ao SUS: representaçôes e práticas de profissionais desenvolvidas nas Centrais de Regulação. Physis, Rio de Janeiro, v. 22, n. 1, p. 119-140, 2012.

GOLDWASSER, R. S. et al. Difficulties in access and estimates of public beds in intensive care units in the state of Rio de Janeiro. Rev. Saúde Pública, São Paulo, v. 50, n. 19, 2016.

KONDER, M. T.; O'DWYER, G. A integração das Unidades de Pronto Atendimento (UPA) com a rede assistencial no município do Rio de Janeiro, Brasil. Interface, Botucatu, v. 20, n. 59, 2016. 
LIEW, D.; KENNEDY, M. P. Emergency department length of stay independently predicts inpatient length of stay. Med J Aust, n. 179, v. 10, p. 524-6, 2003.

LIMA, L. D. et al. Interdependência federativa na política de saúde: a implementação das Unidades de Pronto Atendimento no estado do Rio de Janeiro, Brasil. Ciênc saúde colet., Rio de Janeiro, v. 20, n. 2, p. 595-606, 2015.

NEGRI FILHO, A. A. Bases para um debate sobre a reforma hospitalar do SUS: as necessidades sociais e o dimensionamento e tipologia de leitos hospitalares em um contexto de crise de acesso e qualidade. 2016. 366 f. Tese (Doutorado em Medicina Preventiva) - Faculdade de Medicina, Universidade de São Paulo, São Paulo.

O’DWYER, G. et al. O processo de implantação do Serviço de Atendimento Móvel de Urgência no Brasil: estratégias de ação e dimensóes estruturais. Cad. Saúde Pública, Rio de Janeiro, v. 33, n. 7, 2017a.

O'DWYER, G. et al. Atenção pré-hospitalar móvel às urgências: análise de implantação no estado do Rio de Janeiro. Ciênc. saúde coletiva, Rio de Janeiro, v. 21, n. 7, p. 2189-2200, 2016.

O'DWYER, G. et al. O processo de implantação das unidades de pronto atendimento no Brasil. Rev. Saúde Pública, São Paulo, v. 51, n. 125, 2017 b.

OECD. Average length of stay in hospitals. In: Health at a Glance 2017: OECD

Indicators. Paris: OECD Publishing, 2017.

PINTO, L. F. et al. A regulação municipal ambulatorial de serviços do Sistema Único de Saúde no Rio de Janeiro: avanços, limites e desafios. Ciênc. saúde coletiva, Rio de Janeiro, v. 22, n. 4, p. 1257-1267, 2017.

ROSCOE, J. T. Fundamental Research Statistics for the Behavioural Sciences. New York: Holt Rinehart \& Winston, 1975. 483 p.

\section{Nota}

${ }^{1}$ M.T. Konder participou da concepção, metodologia, coleta e análise de dados e redação final. G. O’Dwyer participou da concepção, metodologia, análise de dados e redação final. 


\section{Abstract}

Emergency Care Units as hospitalization units: phenomena of the care flow in the emergency network

Emergency Health Care delivery has been a major issue in the city of Rio de Janeiro was the target of investments and restructuring with the dissemination of Emergency Care Units (UPAs). Overcrowding, poor quality and integration compromise the conformation of this network. The aim was to analyze the organization and functioning of care flows established in the RUE, based on access to the hospital bed. Thirty-six interviews and data analysis of primary and secondary databases were performed, using descriptive statistics and exploratory analysis. Access to the hospital bed is infrequent, with only $13 \%$ of total requests being met. Bed requests from UPAs reached higher percentages, $40 \%$ for ICUs and $36 \%$ for general practice. However, the remaining $60 \%$ are usually discharged or die before reaching a hospital bed, turning UPAs into inpatient units. Another prominent phenomenon was the conflictual relationship between the prehospital components (primary care and UPA) in the dynamic of the Vaga Zero flow, compromising the continuity of care. It is necessary to improve the level of integration between units that make up the RUE, as well as to expand and qualify the hospital rearward.

Keywords: healthcare coordination and monitoring; health services accessibility; emergency medical services; healthcare delivery. 